\title{
Magnitude of Dental Delay in Trisomy G
}

\author{
STANLEY M. GARN, CYRUS W. STIMSON,* and ARTHUR B. LEWIS
}

Center for Human Growth, University of Michigan, Ann Arbor 48104, The Plymouth State Home and School, Northville, Michigan, and the Fels Research Institute, Yellow Springs, Ohio 45387

Previous reports have suggested delayed dental development in Down's syndrome (mongolism), but without quantification and without exclusion of subjects with cretinism, with a normal chromosomal complement, or with translocations and mosaics of various sorts.

Accordingly, the tooth formation of $25 \mathrm{sub}$ jects with Down's syndrome, verified as trisomy $G$ by karyotyping and excluding subjects with cretinism, was studied radiographically. Standards for tooth formation (crown calcification, root elongation, and alveolar eruption) were those previously described (S. M. GARN, A. B. LEWIS, and D. L. POLACHECK, Science, 128: 1510, 1958; S. M. GARN, A. B. LEWIS, and D. L. Polacheck, I Dent Res 38:135-148, 1959; S. M. GARN, A. B. LEWIS, and R. M. BlizZaRD, J Dent Res 44:243-258, 1965). Dental age assessments were compared to exact chronological ages, calculated from actual birth dates.

As shown in the Ilustration, trisomy $G$ is associated with delayed calcification, root development, and alveolar eruption (seen in oblique- and lateral-jaw views). Of the $25 \mathrm{sub}$ jects studied, 19 had delayed tooth formation, 3 had formation equal in dental and chronological age, and 3 had slightly advanced formation for age and sex. Against the chance hy pothesis the distribution yielded a chi-square value of 11.6 for the $19: 3$ distribution as against the 11:11 hypothesis. The average delay was 0.7 years, a difference significant at

\footnotetext{
This study was supported in part by grant HD02272 from the National Institute of Dental Research, National Institutes of Health, Bethesda, Md.

Additional information available on request to authors.

Received for publication September 2, 1969.

* Present address: Metropolitan Mental Retardation Clinic, 15 Park Row, New York, NY 10038.

Radiographs were taken by Joseph Plesuchenko; computational assistance was given by William $R$. D'Angelo; and the karyotyping was done by Judy A. Stack
}

the $1 \%$ level or better $(t=3.9)$; the percentage delay in dental development was $13 \%$, overall. There was no evidence of a sex difference in the relative magnitude of dental delay.

The $13 \%$ dental delay in trisomy $G$ was less than the $20 \%$ delay in untreated subjects with cretinism and the $33 \%$ delay in subjects with hypopituitarism (S. M. GARN, A. B. LEWIS, and R. M. BlizZard, J Dent Res 44:243-258, 1965). The magnitude of dental delay in these subjects was far less than the delay in appearance of hand-wrist ossification centers in a larger sample from the same institutional population. Trisomy of a $\mathbf{G}$ group chromosome, probably no. 21 delays tooth formation, but to a lesser extent than cretinism and hypopituitarism, and to a lesser extent than postnatal ossification.

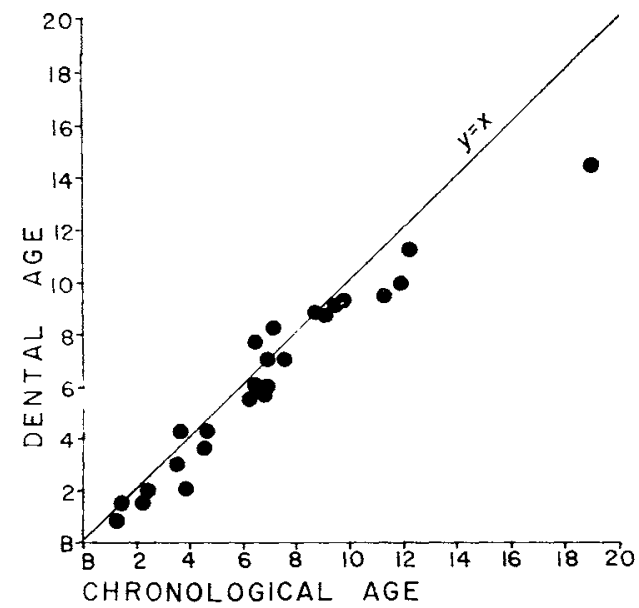

Delay in permanent tooth calcification, root formation, and elongation in 25 subjects with trisomy $\mathrm{G}$. 